Journal of

Online and Distance

Learning

(JODL)

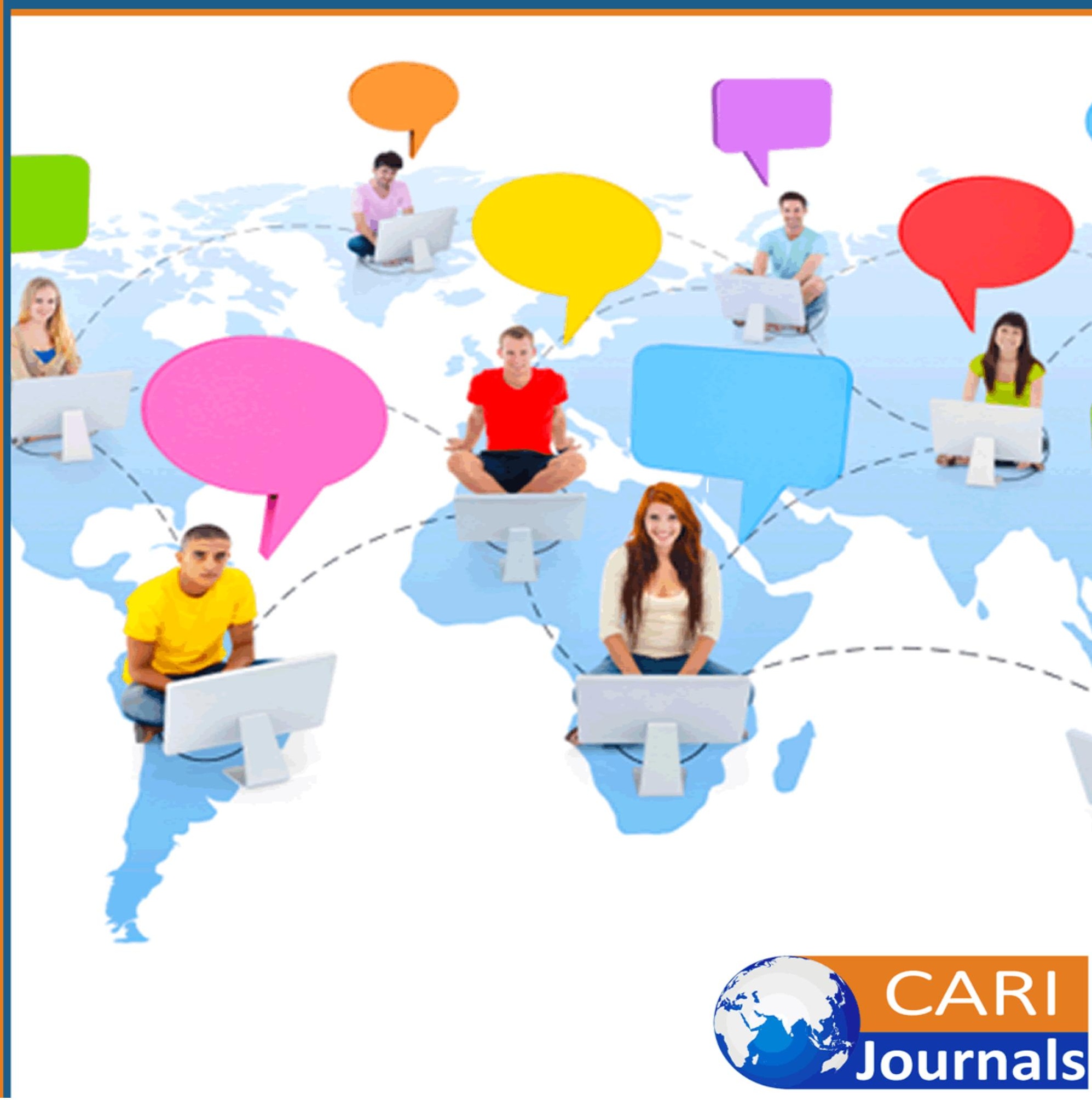




\title{
INFLUENCE OF TECHNOLOGY TYPE ON DEVELOPMENT OF INSTRUCTIONAL MATERIALS FOR DISTANCE EDUCATION.
}

\author{
Hannah Njoki, \\ Department of Education, Mount Kenya University \\ *Corresponding author's Email: hanna@cari.org
}

\begin{abstract}
Purpose: no one technology can support all types of teaching and learning at a distance - the most effective approach is to combine a range of technologies. Using multiple technologies ensure that all learning styles are catered for and that significant opportunities for interaction between the learner and the tutor are provided. The general objective of the study was to evaluate influence of technology type on development of instructional materials for distance education.
\end{abstract}

Methodology: The paper used a desk study review methodology where relevant empirical literature was reviewed to identify main themes and to extract knowledge gaps.

Findings: From the study findings, it is concluded that learning through experience influences the creation of new values which become attitudes that have a strong impact on teacher's behavior towards e-learning technology. Therefore, the attitude and values are singled out as a separate category as well, linking together certain factors that influence them. Because of the manner of academic teaching process, the most commonly used is blended learning model where a course instructor chooses the e-learning technology based on certain elements. The practice has shown that creating a blended learning environment is not easy and that course instructors have problems in many stages of designing the virtual learning environment, from the analysis of the course requirements, analysis of the student requirements, application of instructional design model, elearning technology use, not understanding the concept of the quality of e-learning process and many other factors..

Recommendations: The study recommends that is a need for more courses should be integrated in distance learning so as to cover all the courses offered to students. There is also need for students to enroll in practical classes for computer training. This will enable the less net savvy students to brace up so as to avoid being left behind by others. There is no doubt that a lot of pressures are facing our students when it comes to distance learning technology adoption, especially distance barrier. There is therefore, need for e-learning to be fully put in place to enable the group of students that their homes are far away from the school to participate in classes even when they are not able to make it to school. Finally, there should be availability of ICT infrastructure, the absence or inadequacy of which will totally hamper the idea of e-learning adoption in universities. There should be provision of computers and high bandwidth to enable the easy flow of classes online.

Keywords: influence, technology type, development, instructional materials, distance education 
Journal of Online and Distance Learning

Vol.1, Issue1, pp $60-74,2021$

www.carijournals.org

\subsection{INTRODUCTION}

\subsection{Background of the Study}

The idea of distance learning as the concept of learning at one's own pace independent of time and place, originated in 19th century. The Open University of United Kingdom, which introduced blended learning in 1969, had the crucial role in introducing the distance learning into the higher education. The term e-learning (electronically supported learning) was introduced in 1995, and its most common definition is: learning and teaching using information and communications technology, or more broadly, e-learning technology. Blended model of learning combines different models of learning and teaching: in traditional classroom (which provides elearning technologies) and virtual learning environment. Virtual Learning Environment (VLE) is a component or subsystem of the Managed Learning Environment (MLE), where students and teachers take part in different types of online interaction, and whose focus is on managing and facilitating the learning process while providing the required resources. The commonly used synonym for VLE is Learning Management System (LMS). MLE includes various information systems and processes of the higher education, and together with VLE they make a part of virtual campus (The Joint Information System Committee [JISC], 2019). Today, rapid changes and advances occurring in social, cultural, economic, technological and political areas affect the aspects of social life; hence, education systems need to be renewed Salloum (2019). Moreover, scientific and technological advances lead to fundamental changes in social and economic life in the one hand, and also in the concepts and approaches acquired in the process of education on the other hand (Alkan, 1996). One of those concepts and approaches is distance education.

Physical separation of the student and instructor for the duration of the course is one of the key identifiers for distance education. Lectures, tutorials, and for the most part, student assistance or support, is provided through electronic media (Usun, 2016). Yellen failed to mention another important component involved; distance education often possesses the characteristic of physical separation of the student from other students. Gray. (2016) felt their study of 250 institutions validated earlier study findings on characteristics of distance education programs. They agreed that there was no uniformity in the size of distance education programs; these programs were directed at capturing the nontraditional student; and faculty and student interacted by using several different forms of asynchronous and synchronous communication media. Distance education is heavily entrenched in technology. For communicating alone, there are a variety of methods. The most popular and common methods of communication used is electronic mail (e-mail); bulletin board systems (BBS); Internet (using chat programs); telephone-based audio conferencing; and video conferencing with 1- or 2-way video and 2-way audio via broadcast; and closed-circuit or low power television (Sherry, 1996). Of the choices for course delivery, ITV (interactive television), television, video, and computer-based (web-based/Internet) (Gray,2016), web-based courses have shown to be the least expensive for institutions to provide .

Web-based courses have also experienced the greatest growth and are "the primary means by which colleges and universities provide distance learning" (Garcia, 2015) which some attribute to the cost incurred in an online course versus a video teleconferencing course (Effendi,2015). Trends provide projections on what is expected for the future. Many program decisions are made based on this invaluable information. In order for administrators to make the "right" decisions, the study 
of trends on all facets of distance education is required. Institution Involvement. The Internet has grown at an expeditious rate. Consider that 38 years passed before it reached 50 million users (Rakap,2015) and television was only slightly quicker, taking 30 years. The World Wide Web, on the other hand, earned that honor in only four years (Miller \& King). Technology advancements are at the heart of the increased popularity and demand of distance education statement that there is no indication of enrollments leveling off. Every one is jumping on the band wagon. A market survey administered in 2000 showed $94 \%$ of all colleges were either offering $(63 \%)$ or planning to offer $(31 \%)$ distance education courses (Dawson ,2015). Post-secondary schools are not the only ones 28 engaged in distance education. Business and industry are also pursing what appears to be a lucrative enterprise (Zacharius,2011). This should come as no surprise since distance education appears to be going nowhere but straight up. Ludlow (2014) recognized the changing demographics and needs of students in higher education. He believes universities have increased their focus on recruiting students over the age of 22 since the mid-1970s. Some institutions believe distance education is the main attraction in drawing non-traditional student enrollments (Ludlow, as cited by Easton, 2003). Worley (2020) also agreed with Ludlow's statement but added that much of the growth of distance education has been fueled by those employed professionally. Traditional educational environments, for the most part, fail to provide the flexibility necessary for those with commitments to family and work. Consequently, adult learners are expounded to be one of the fastest growing groups enrolling in higher education (Worley, 2020), and to some extent, this growth is considered due to the availability of distance education (Boettcher, 2016).

Most University e-Learning programmes have been designed to increase access to higher education, especially for non-traditional students. In a recent survey on the importance of various goals to institutions' distance education program (a high proportion of which use online technology as a primary or supporting medium of instruction), two out of three United States of America fouryear public institutions indicated that increasing student access was a very important goal; either by "making courses available at convenient locations" (72\%), or by "reducing time constraints for course taking" (66\%), (Demuyakor, 2020). The corresponding figures for four-year private institutions were also high (65\% and $61 \%$ respectively). In Europe, as well, there is abundant evidence to show that widening access to their programmes - and to their related academic resources - is an important objective of many university e-learning strategies; reaching new groups of students (women and other marginalised groups) is an additional and closely related goal (UNESCO, 2000). According to (Demuyakor, 2020), Open and Distance Learning offers opportunities for countries to meet the new and changing demands for education and training. Open and Distance Learning is both complementary and under certain circumstances an appropriate substitute for the face-to-face methods that still dominate most educational systems. The advantages of Open and Distance Learning are seen more in terms of the learner through more freedom of access, and thereby a wider range of opportunities for learning and qualification. The barriers that may be overcome by distance learning include not only geographical distance, but also other confining circumstances, such as personal constraints, cultural and social barriers and lack of educational infrastructure (Ali, 2020).

UNESCO (2002) define distance education as any educational process in which all or most of the teaching is conducted by the teacher removed in space and/or time from the learner, with the effect that all or most of the communication between the two is through an artificial 3 medium, either 
electronic or print. According to Abdarahim, (2018) distance education implies that the majority of educational communication between the teacher and the students occurs non-contiguously (at different times and at separate places - separating the instructor tutor from the learner). It must involve two-way communication for the purpose of facilitating and supporting the educational process. It uses technology to mediate the necessary two-way communication. According to Nzuki, (2015) the purpose of distance education is based on the principle of equality of opportunity for all. This is largely the mission of distance education which emphasizes the expansion of education for self - employment and for quality life. The philosophy of distance education also emphasizes the need for individually educated population that can contribute to social and economic development of the society. They contend, distance education is particularly attractive and affordable to a majority of adult learners.

According to Levin (2018), distance learning is a viable investment for adult learners who may have only had access to lower level or non-degree courses. Distance education is also helping universities serve a formerly unservable audience, Levin (2018).Ghosh,(2018) report that distance education appeals to adult learners since they do not have to give up their jobs during study, they do not have to be away from their families for a long period of time, or have to worry about lecturers and sessions and have an opportunity to attend residential sessions for shorter periods. According to Phelan, Mendoz aDiaz, and Mathews (2020), distant learners always enjoy flexibility in terms of choosing the place and time of study. According to Common Wealth of Learning (2015), adult learners seek higher education through distance learning primarily to get a job, gain a better job or a promotion, and earn a higher income.

For employers, open and distance learning offers the possibility of organizing learning and professional development in the workplace itself, which is often more flexible and saves costs of travel, subsistence etc. The use of distance learning often puts both the firm and employees in a position of co - investment (of money and time) in the pursuit of common goals, based on shared values and culture. It increases productivity and supports the development of communication and other work-related skills. With sufficient numbers of employees being trained, open and distance learning is usually cost-effective. Other advantages for the employer include the increased availability of the employee during the course of the training programme, and the portability of training programmes and processes (UNESCO, 2020). Distance learning also serves many good purposes from an institution's point of view. Through technology, students who live great distances from an institution can be served. Adult learners can enroll in college course work at convenient times and in more convenient locations. College and university administrators recognize that instructors can teach more students without increasing the need for additional staff. Full-Time- Enrollment increases with distance education, thus, providing schools with additional state income with little additional expense (Major \& Levenburg, 2017). The place of distance education in increasing access to higher education worldwide cannot be understated.

According to Kanwar \& Uvalić-Trumbić, (2017), higher education has expanded remarkably in recent decades. Growth is, by all means, faster than anticipated. Van der Wende, (2018) reports that 120 million students are expected to be enrolled in higher learning institutions worldwide by 2020, but that number has already been achieved. Santiago, Tremblay, Basri, \& Arnal, (2018) report that in 2004, 132 million students were enrolled worldwide, up from 68 million in 1991. 
Average annual growth from 1991 to 2004 was 5.1 per cent. Most of this growth has been in Africa, Asia, Latin America and the Caribbean, the Arab countries, and in Eastern and Central Europe. UNESCO, (2019) reports that distance education represents an area of enormous potential for higher education systems around the world struggling to meet the needs of growing and changing student populations. For several decades the sector has been dominated by largescale 'open' universities (Indira Gandhi National Open University in India counts 1.8 million students). The University of South Africa UNISA claims to be the continent's premier distance learning institutions with approximately 250,000 students. The African Virtual University works across borders and language groups in over 27 countries Cambridge UK. UNESCO (2009) further notes that much of the appeal of distance education is attributed to its ability to accommodate the needs of a wide variety of learners (students located far from educational centers, employed adults, women who are attempting to balance family and school commitments) and even the incarcerated.

According to Mehrotra, Hollister, and McGahey, (2011), distance education, is not a future possibility for which higher education must prepare, it is a current reality creating opportunities and challenges for educational institutions; a reality offering students expanded choices in where, when, how, and from whom they learn; a reality making education accessible to ever larger numbers of persons. Lockwood, 1993 contends that since the learners and the instructors are geographically isolated, distance learning relies largely on electronic devices and print materials for instructional delivery. Mbwesa (2010) Journal of Continuing Open and Distance Education, states that the extent, to which teachers perceive a certain pedagogic approach as being effective, will influence greatly the extent to which they appreciate and adopt new innovations. Quoting from her research on the use of WEDUSOFT software as a learning management system, it can be noted that many of her respondents perceived it as an effective management learning system in the University of Nairobi. Gakuu, and Kidombo, (2010) in the same journal on pedagogical integration of ICT in curriculum delivery notes that it is influenced by the ownership of the institutions, ICT policy and the manager's level of ICT skills. That the Kenya government should develop and implement as ICT policy on education.

\subsection{Statement of the Problem}

According to Manrique and Bressler (2016), in spite of the increase in the number of Distance Learning Programs (DLP) offered by higher education institutions, not all programs have been successful. Successful programs use different types of media resources for instructional delivery. Holden \& Westfall, 2010 argue that when selecting the most appropriate instructional media for distance learning, consideration must be given to a number of variables that may influence the selection of one medium over another. Bates (2011) reports that despite the increased capacity of information and communication technologies to support distance education, their impact in higher education has been "slow and marginal" particularly in least developed countries. The tendency in higher education is to "fit" technology into traditional university structures and use it to deliver education in traditional ways rather than to use technology as a change lever to help create new teaching and learning paradigms (Olcott, 2020). Jurich (2020) associates the slow and marginal uptake of technology in distance learning to faculty "fear of technology" that limits the faculty's ability to take full advantage of learning technologies in support of distance learning. Merisotis \& Phipps, (2019) also note that students may be inexperienced with using technology, particularly 
educational technology. This study therefore seeks to explore factors that influence the choice of technology for the development instruction materials for distance education.

\subsection{Objectives of the Study}

The general objective of the study was to evaluate influence of technology type on development of instructional materials for distance education.

\subsection{Justification and Significance of the Study}

The findings of the study will also create a basis for future research on technology in distance education in globally. This research is expected to be useful to in private institutions such as those offering continuous in house on job training such as banks, mobile staff in order to improve manpower service provider skills, universities offering adult learning programs. Cooperative societies offering entrepreneurship knowledge to its retiring members, government ministries offering programmes that aims at improving staff performance, international organizations offering further education support in developing countries, among stakeholders in education sector.

\subsection{LITERATURE REVIEW}

\subsection{Theoretical review}

Two theories were found to be relevant in evaluating influence of technology type on development of instructional materials for distance education. The theories that were found to best inform the research constructs are theory of industralization, (1988) and Technology Acceptance Model Theory (Vankatesh, 2008).

\subsubsection{Theory of Industrialization}

In the theory of Industrialization of Teaching Peters (1988) viewed distance education as an industrialized form of teaching and learning. Peters suggested that distance education allowed principles of economic and industrial theories to be applied in the design and delivery of instruction. Peters concluded that principle of the division of labor is an integral part of distance teaching. Peters characterized distance education as a method of imparting knowledge, skills and attitudes which is rationalized by the application of division of labor and organizational principles as well as by the extensive use of technical media, especially for the purpose of reproducing high quality teaching material which makes it possible to instruct great numbers of students at the same time wherever they live. Distance education was therefore described as an industrialized form of teaching and learning. This model emphasizes instructional units as products which can be mass produced and distributed like cars or washing machines..

\subsection{Technology Acceptance Model Theory}

This study adopted the Technology Acceptance Model Theory (TAM) of Vankatesh \& Bala (2008) which is greatly referred to as Information System Theory (IST). This theory shows how the users take time to accept and use any new technology disposed to them. Vankatesh and Balla (2008) emphasize that technologies which are new like personal computers or any other, are complicated from the beginning and there exist an element of uncertainty in the minds of the may- 
be makers of decisions with respect to adopting them successfully. In this situation people form intentions and attitudes towards making effort in learning how to use the technology that is new before initiation of efforts which are directed at using. Attitudes towards using and the intentions to use can be poorly-formed or lack conviction or else can only occur only after preliminary striving in learning how to use the new technology that evolves. This means that the real usage may not have immediate or direct consequence of such intentions and attitudes. The Technology Acceptance Model Theory continues to state that subject norms, perceived behavioral control and attitudes shape every individual intention it takes in engagement in a specific time and place. Behavioral intentions are influenced by the attitudes of individuals basing on pre-expected outcomes in terms of risks and benefits not yet seen or experienced. Behaviour depends on both motivation (intension) and (behavioral control). The six constructs influencing a person's behavior are namely; attitude to evaluate, strength of intension, degree of approval (are many people benefiting?), social norms-(what is the trend?) Power of impediments (can I get over or not?), perceptions- (easy or difficult?).This theory will add to the study as it helps in evaluation of adoption of modern online learning as transits from the traditional learning process

\subsection{Empirical Review}

Laichena , (2017) conducted a study set out to ascertain the types of learner support services offered to open, distance and e-learning students as well as identify learner support services that the students and the administrators felt were essential for effective learning. The study also intended to establish the attitudes of the users of open, distance and e-learning programmes on the learner support services offered and identify the factors that influence learner support services offered in open, distance and e-learning programmes in selected public universities in Kenya. The study limited itself to fourth year students undertaking a bachelor's degree programme only. This study was guided by the systems approach model whereby the types of learner support services offered by an institution enhances the success of open, distance and e-learning programmes through provision of adequate learner support services. Literature reviewed on the categories of services such as teaching and learning needs, access of information and personal and social needs (independent variables) showed that they determine the overall satisfaction of learner support services (dependent variable) offered. The study adopted a descriptive survey design. Purposive sampling was used to select three public universities offering open, distance and e-learning programmes, namely Egerton University, Kenyatta University and the University of Nairobi. Further, purposive sampling method was also used to select three study regions where each of the three universities had a study centre. A sample size of 329 fourth year students in the selected universities was arrived at using tables instituted by Morgan and Krejcie (1970). Stratified sampling technique was used to get a representation of students from each university while convenience sampling was used to select the students at each study centre from each university. All the administrators (directors and coordinators) were used in the study. The study instruments (interview schedules and questionnaires) were constructed to help in data collection. The data collected was coded, analysed and tabulated using the SPSS version 20 programme. Results were presented in form of frequency distribution tables and graphs. The study established that students rated majority of learner support services offered by their institutions across the three universities as poor while the administrators indicated that the services offered were good. However, the students and the administrators were of the opinion that there were essential learner support 
services that were very necessary to open, distance and e-learning students. Further, there was a consensus by the students and the administrators that the services offered were necessary though they needed to be improved. Lastly, the study found out that the administrators were aware of the essential learner support services but were limited by other factors that were beyond their control. The study recommends that; institutions offering open, distance and e-learning programmes should constantly assess the value of learner support services offered by constantly seeking the students ${ }^{\text {ee }}$ opinion and offer few but essential learner support services that are of high quality, adequate, of good quality and satisfactory to the students.

Nderitu, (2013) carried a study to find out the effect of time management of academic performance a study was carried out. A total number of 650 students were selected using stratified random sampling technique. This sample was taken from 4,500 University of Nairobi students who were registered for B.Ed degree in different levels of study in the school of continuing and distance Education. A mixed mode method approach was used in data collection. Correlational research design was employed in data analysis. Pearson correlations were used to establish if there was a relationship between time management and academic performance. The analysis indicated a strong relationship between time management and academic [ $\mathrm{r}=0.569]$. The value of $\mathrm{r} 2=0.324$, indicated that time management accounts for about $32.4 \%$ of the variation in average performance.

Mwiti,(2012) conducted a study to investigate the factors that affect learning of learners with visual impairments learning through distance education; a case of Kenya Institute of Special Education. The study was guided by three research objectives; such as to investigate the effect of teaching and learning strategies in promotion of learning of learners with visual impairments learning through distance education; a case of Kenya institute of special education, to investigate the effect of the environmental modification and adaptation in learning of learners with visual impairments learning through distance education; a case of Kenya institute of special education, and to establish the extent to which learner support services available influence learning of learners with visual impairments learning through distance education; a case of Kenya institute of special education. The target population was drawn from the face to face tutorial centers, where the learners with visual impairments attend their tutorial sessions. The learners in these centers represented all other learners in the country in other institutions of higher learning offering studies through distance education mode. A survey research design was used for this study. The factors that affect learning of learners with visual impairments learning through distance education were studied based on the three research objectives. The data was processed using statistical package for social science. The results of the findings in the study revealed that Kenya institute of special education had tried in providing accessible education to learners with visual impairments learning through distance education mode. However, there are various aspects that require improvements such as provision of all learning materials in braille and large print, audio cassettes, recorded lectures, and closed circuit televisions to enhance learning of students with visual impairments, studying through distance education. The study also found out that there is need to improve on environmental modification and adaptation and also need to improve on learner support services at the face to face tutorial centres. The researcher recommends that KISE should provide appropriate and adequate teaching and learning materials, ensure that students are provided with appropriate and conducive learning environments and that they are provided with adequate learner 
support services by professional counselors who understands and knows how to handle students with visual impairments

Kitua, (2012) conducted a study aimed at identifying the factors that influence the use of the internet in learning at the Meru extra mural center. The study strived to determine the use of the internet as a channel of communication used in learning as well as the social, student and university related factors affecting the use of this channel of communication. The researcher employed descriptive survey design, gathering information from distance education students and the staff at the Meru extra mural centre using questionnaires. Quantitative data was analyzed according to the objectives using descriptive statistics to show a comparison between factors while inferential statistics specifically the independent sample t-test was used to determine the relationships between the dependent and the independent variables. Data was then presented in form of tables and charts for interpretation. The social factors identified were found not to have significant effect on frequency of use of internet by distance learners while the university and learner factors had significant effects on use of internet by distance learners. The researcher recommends that the university should offer computer training for all students and allow free access to university computers and internet.

Kubai, (2011) conducted a study on factors influencing health workers satisfaction with training through distance learning mode of study. The objectives of the study were to determine how accessibility to technology, Learner education background, delivery modes, efficacy with technology and gender influences on learner satisfaction with distance learning. This study employs the case study research design to be able to gather particular data on the health workers satisfaction with training through distance learning mode of study. The sample consisted of 10\% of the total population, that is eighty seven students $(n=87)$. Systematic random sampling procedure was used to arrive at the sample of students. To facilitate fast and convenient collection of data, questionnaires were used. The collected data was recorded and analyzed using both qualitative and quantitative methods. SPSS (Statistical Package for Social Science) was used to aid the process of data analysis. The findings indicated that both slow internet connectivity and lack of internet connectivity influenced the accessibility to technology and therefore influenced on learner satisfaction with distance learning. From the study results it was clear that learners' educational background was a key factor that contributed to learner's level of satisfaction in distance learning. Pertaining gender it was revealed that in AMREF Training center female students had higher representation in distance learning compared to male students. Based on these study findings, recommendations drawn include: Distance learning institutions should provide learner support services in form of physical facilities, such as libraries, ICT, provide access to course resources as mechanisms important to student learning and development.

\subsection{Research gaps}

Geographical gap is a knowledge gap that considers, the untapped potential or missing/limited research literature, in the geographical area that has not yet been explored or is under-explored. For instance, Mwiti, (2012) conducted a study to investigate the factors that affect learning of learners with visual impairments learning through distance education; a case of Kenya Institute of Special Education. A survey research design was used for this study. The results of the findings in the study revealed that Kenya institute of special education had tried in providing 
accessible education to learners with visual impairments learning through distance education mode. The study presented a geographical gap as it was done in Kenya while our current study sought to evaluate influence of technology type on development of instructional materials for distance education.

Methodological gap is the gap that is presented as a result in limitations in the methods and techniques used in the research (explains the situation as it is, avoids bias, positivism, etc. Laichena , (2017) conducted a study set out to ascertain the types of learner support services offered to open, distance and e-learning students as well as identify learner support services that the students and the administrators felt were essential for effective learning. The study adopted a descriptive survey design. Purposive sampling was used to select three public universities offering open, distance and e-learning programmes, namely Egerton University, Kenyatta University and the University of Nairobi.The the study found out that the administrators were aware of the essential learner support services but were limited by other factors that were beyond their control. The study recommends that; institutions offering open, distance and e-learning programmes should constantly assess the value of learner support services offered by constantly seeking the students ${ }^{\text {ee }}$ opinion and offer few but essential learner support services that are of high quality, adequate, of good quality and satisfactory to the students. The study presented a methodological gap as it was subjected to descriptive research design while our current study adopted a desktop literature review method.

Conceptual gap arises because of some difference between the user's mental model of the application and how the application actually works. Nderitu, (2013) carried a study to find out the effect of time management of academic performance a study was carried out. A total number of 650 students were selected using stratified random sampling technique. Correlational research design was employed in data analysis. Pearson correlations were used to establish if there was a relationship between time management and academic performance. The analysis indicated a strong relationship between time management and academic [ $\mathrm{r}=0.569]$. The value of $\mathrm{r} 2=0.324$, indicated that time management accounts for about $32.4 \%$ of the variation in average performance. The study presented a conceptual gap as it sought to evaluate influence of technology type on development of instructional materials for distance education.

\subsection{METHODOLOGY}

The study adopted a desktop literature review method (desk study). This involved an in-depth review of studies related to influence of technology type on development of instructional materials for distance education. Three sorting stages were implemented on the subject under study in order to determine the viability of the subject for research. This is the first stage that comprised the initial identification of all articles that were based on influence of technology type on development of instructional materials for distance education from various data bases. The search was done generally by searching the articles in the article title, abstract, keywords. A second search involved fully available publications on the subject on influence of technology type on development of instructional materials for distance education. The third step involved the selection of fully accessible publications. Reduction of the literature to only fully accessible publications yielded specificity and allowed the researcher to focus on influence of technology type on development of 
instructional materials for distance education which was split into top key words. After an in-depth search into the top key words (influence, technology type, development, instructional materials , distance education), the researcher arrived at 5 articles that were suitable for analysis. The 5 articles were findings from Laichena, (2017) who conducted a study set out to ascertain the types of learner support services offered to open, distance and e-learning students as well as identify learner support services that the students and the administrators felt were essential for effective learning. The study adopted a descriptive survey design. Purposive sampling was used to select three public universities offering open, distance and e-learning programmes, namely Egerton University, Kenyatta University and the University of Nairobi. The study established that students rated majority of learner support services offered by their institutions across the three universities as poor while the administrators indicated that the services offered were good.

Nderitu, (2013) who carried a study to find out the effect of time management of academic performance a study was carried out. A total number of 650 students were selected using stratified random sampling technique. Correlational research design was employed in data analysis. Pearson correlations were used to establish if there was a relationship between time management and academic performance. The analysis indicated a strong relationship between time management and academic $[\mathrm{r}=0.569]$. The value of $\mathrm{r} 2=0.324$, indicated that time management accounts for about $32.4 \%$ of the variation in average performance.

Mwiti, (2012) who conducted who a study to investigate the factors that affect learning of learners with visual impairments learning through distance education; a case of Kenya Institute of Special Education. A survey research design was used for this study. The results of the findings in the study revealed that Kenya institute of special education had tried in providing accessible education to learners with visual impairments learning through distance education mode.

Kitua, (2012) who conducted a study aimed at identifying the factors that influence the use of the internet in learning at the Meru extra mural center. The researcher employed descriptive survey design, gathering information from distance education students and the staff at the Meru extra mural centre using questionnaires. The social factors identified were found not to have significant effect on frequency of use of internet by distance learners while the university and learner factors had significant effects on use of internet by distance learners. The researcher recommends that the university should offer computer training for all students and allow free access to university computers and internet.

Kubai, (2011) who conducted a study on factors influencing health workers satisfaction with training through distance learning mode of study. This study employs the case study research design to be able to gather particular data on the health workers satisfaction with training through distance learning mode of study. From the study results it was clear that learners' educational background was a key factor that contributed to learner's level of satisfaction in distance learning

\section{SUMMARY, CONCLUSION AND POLICY IMPLICATION FOR FURTHER STUDY}

\subsection{Summary}


Distance education has gone through several stages of development. Taylor, (1999) has proposed five generations of distance education: Correspondence education; Integrated use of multiple, oneway media such as print, broadcasting or recorded media such as videocassettes; Two-way, synchronous tele-learning using audio or video-conferencing; Flexible learning based on asynchronous online learning combined with online interactive multimedia; Intelligent flexible learning, which adds a high degree of automation and student control to asynchronous online learning and interactive multimedia.

\subsection{Conclusion}

From the study findings, it is concluded that learning through experience influences the creation of new values which become attitudes that have a strong impact on teacher's behavior towards elearning technology. Therefore, the attitude and values are singled out as a separate category as well, linking together certain factors that influence them. Because of the manner of academic teaching process, the most commonly used is blended learning model where a course instructor chooses the e-learning technology based on certain elements. The practice has shown that creating a blended learning environment is not easy and that course instructors have problems in many stages of designing the virtual learning environment, from the analysis of the course requirements, analysis of the student requirements, application of instructional design model, e-learning technology use, not understanding the concept of the quality of e-learning process and many other factors..

\subsection{Recommendations}

Students are ready to adopt distance learning technologies, it is therefore recommended that more courses should be integrated in distance learning so as to cover all the courses offered to students. There is also need for students to enroll in practical classes for computer training. This will enable the less net savvy students to brace up so as to avoid being left behind by others. There is no doubt that a lot of pressures are facing our students when it comes to distance learning technology adoption, especially distance barrier. There is therefore, need for e-learning to be fully put in place to enable the group of students that their homes are far away from the school to participate in classes even when they are not able to make it to school. Finally, there should be availability of ICT infrastructure, the absence or inadequacy of which will totally hamper the idea of e-learning adoption in universities. There should be provision of computers and high bandwidth to enable the easy flow of classes online. This goes in line with the recommendation given by Abdel-Wahab (2008) that 'if the high ICT infrastructure for e-learning is unavailable, the sequential use of predecessor distance learning technologies from correspondence courses to radio, TV, CD-ROM, Internet and World Wide Web is recommended. Such a sequential use of predecessor distance learning technologies is poised to leverage the experience into a significant use of learning

\subsection{REFERENCES}

Abdrahim, N. A. (2018). Practices in Malaysian Higher Education. International Journal of Academic Research in Business and Social Sciences, 8(12).

Ali, W. (2020). Online and remote learning in higher education institutes: A necessity in light of COVID-19 pandemic. Higher Education Studies, 10(3), 16-25. 
Ali, Wahab. "The Efficacy of Evolving Technology in Conceptualizing Pedagogy and Practice in Higher Education." Higher Education Studies 9, no. 2 (2019): 81-95.

Dawson, B. A., \& Fenster, J. (2015). Web-based social work courses: Guidelines for developing and implementing an online environment. Journal of Teaching in Social Work, 35(4), 365-377.

Demuyakor, J. (2020). Coronavirus (COVID-19) and online learning in higher institutions of education: A survey of the perceptions of Ghanaian international students in China. Online Journal of Communication and Media Technologies, 10(3), e202018.

Effendi, H., Soenarto, S., \& Sofyan, H. (2015). The effectiveness of web-based interactive blended learning model in electrical engineering courses. REiD (Research and Evaluation in Education), 1(2), 175-185.

Garcia, I., Guzmán- Ramírez, E., \& Pacheco, C. (2015). CoLFDImaP: A web- based tool for teaching of FPGA- based digital image processing in undergraduate courses. Computer Applications in Engineering Education, 23(1), 92-108.

Ghosh, D., Gupta, A., \& Levine, S. (2018). Learning actionable representations with goalconditioned policies. arXiv preprint arXiv:1811.07819.

Gray, J. A., \& DiLoreto, M. (2016). The effects of student engagement, student satisfaction, and perceived learning in online learning environments. International Journal of Educational Leadership Preparation, 11(1), n1.

Kapasia, N., Paul, P., Roy, A., Saha, J., Zaveri, A., Mallick, R. \& Chouhan, P. (2020). Impact of lockdown on learning status of undergraduate and postgraduate students during COVID19 pandemic in West Bengal, India. Children and Youth Services Review, 116, 105194.

Kerres, M. (2020). Against all odds: Education in Germany coping with Covid-19. Postdigital Science and Education, 2(3), 690-694.

Kitua, D. M. (2012). Factors influencing the use of the internet in learning among Bachelor of Education (Arts) Distance Learners: a case of the Meru Extra Mural Centre, University of Nairobi (Doctoral dissertation, University of Nairobi, Kenya).

Kubai, J. (2011). Factors influencing health workers' satisfaction with training by Distance Learning Mode: the case of AMREF Training Centre in Nairobi (Doctoral dissertation, University of Nairobi, Kenya).

Levin, S., Fulginiti, A., \& Moore, B. (2018). The perceived effectiveness of online social work education: Insights from a national survey of social work educators. Social Work Education, 37(6), 775-789.

Levine, A. (2018). Privatization in higher education. In Privatizing education (pp. 133-148). Routledge. 
Lorikiriki, A. L. (2016). Factors influencing guidance and counseling programme in the integration of learners with visual impairments and strategies for its enhancement in public primary schools in Turkana South Sub-County, Turkana County, Kenya (Doctoral dissertation, Egerton University).

Mbithi, B. M. (2013). Influence of financial transactions through mobile phones on the growth of Safaricom agents in Kisumu county, Kenya (Doctoral dissertation, University of Nairobi).

Mitra, S., \& Mitra, J. C. Education after covid-19 (real pandemic). : 2020, 187.

Muriungi, D. N. (2015). The contribution of private universities to the development of higher education in Kenya the case of Kenya Methodist University (1997-2013) (Doctoral dissertation, University of Nairobi).

Murphy, M. P. (2020). COVID-19 and emergency eLearning: Consequences of the securitization of higher education for post-pandemic pedagogy. Contemporary Security Policy, 41(3), 492-505.

Nderitu, A. (2013). The effect of time management on academic performance of distance learners: A case of the University of Nairobi distance learners.

Nzuki, P. K., Bowa, O., Gunga, S. O., \& Origa, J. O. (2015). The Relationship Between Perceived Quality Dimensions and Growth in Distance Education: The Case of External Degree Programme of the University of Nairobi, Kenya. International Journal for Innovation Education and Research, 3(2), 87-105.

Oirere, G. G. Month: August 2018.

Owen, J. M. (2020). Program evaluation: Forms and approaches. Routledge.

Rakap, S., Jones, H. A., \& Emery, A. K. (2015). Evaluation of a web-based professional development program (Project ACE) for teachers of children with autism spectrum disorders. Teacher Education and Special Education, 38(3), 221-239.

Rao, S., \& Krishnan, V. (2014, December). Distance education. In Nitte University, Fourth International Conference on Higher Education: Special Emphasis on Management Education.

Sahu, P. (2020). Closure of universities due to coronavirus disease 2019 (COVID-19): impact on education and mental health of students and academic staff. Cureus, 12(4).

Salloum, S. A., Alhamad, A. Q. M., Al-Emran, M., Monem, A. A., \& Shaalan, K. (2019). Exploring students' acceptance of e-learning through the development of a comprehensive technology acceptance model. IEEE Access, 7, 128445-128462.

Shackman, G. (2018). What is Program Evaluation? A Beginners Guide (Presentation Slides). A Beginners Guide (Presentation Slides)(February 11, 2018). 
UŞUN, S. (2016). A review on the program evaluation strategies in distance education. International Journal on New Trends in Education \& Their Implications (IJONTE), 7(3).

Zacharis, N. Z. (2011). The effect of learning style on preference for web- based courses and learning outcomes. British Journal of Educational Technology, 42(5), 790-800.

Zhu, X., \& Liu, J. (2020). Education in and after Covid-19: Immediate responses and long-term visions. Postdigital Science and Education, 2(3), 695-699. 